\title{
QUALIDADE DAS ÁGUAS DE POÇOS RASOS EM ÁREA COM DÉFICIT DE SANEAMENTO BÁSICO EM CUIABÁ, MT: AVALIAÇÃO MICROBIOLÓGICA, FÍSICO- QUÍMICA E FATORES DE RISCO À SAÚDE
}

\author{
B. R. BRUM, N. R. OLIVEIRA, H. C. O. REIS, Z. M. LIMA e E. B. MORAIS* \\ Universidade Federal de Mato Grosso \\ ebmorais@ufmt.br
}

Artigo submetido em janeiro/2016 e aceito em fevereiro/2016

DOI: $10.15628 /$ holos.2016.2714

\section{RESUMO}

As doenças de veiculação hídrica são responsáveis por milhões de mortes todos os anos no mundo. Tais doenças estão relacionadas à falta de saneamento básico e água de qualidade para consumo humano. Em Cuiabá, MT, o bairro Pedra 90 apresenta problemas relacionados à falta de água em condições adequadas de quantidade e qualidade, o que levou a população a construir poços rasos em suas residências para garantir um abastecimento alternativo. Este trabalho avaliou a qualidade das águas de dezessete desses poços e identificou que os mesmos apresentam contaminação por Escherichia coli e bactérias heterotróficas, provavelmente por estarem próximos às fossas rudimentares que são comuns na região. O consumo dessas águas representa risco à saúde da população.

PALAVRAS-CHAVE: Doenças de Veiculação Hídrica, Escherichia coli, Fossas Rudimentares, Bairro Pedra 90.

\section{WATER QUALITY OF SHALLOW WELLS IN AREA WITH LACK SANITATION IN CUIABÁ, MT: MICROBIOLOGICAL AND PHYSICAL-CHEMICAL EVALUATION AND HEALTHY RISKS FACTORS}

\begin{abstract}
Waterborne illnesses are responsible for millions of deaths every year in the world. These illnesses are related to lack sanitation and unsafe water for human consumption. In Cuiabá, MT, the Pedra 90 Neighborhood has problems related to quality and quantity of water which led people to build shallow wells in their residences to ensure an alternative supply. This study evaluated the
\end{abstract}

water quality of seventeen of these wells and found that they are contaminated by Escherichia coli and heterotrofic bacteria. The proximity of the wells to rudimentary tanks, that are common in the region, can explain this microbiological contamination. The consumption of this unsafe water can be harmful to population health.

KEYWORDS: Waterborne Illnesses, Escherichia coli, Rudimentary Tanks, Pedra 90 Neighborhood. 


\section{INTRODUÇÃO}

Dados recentes indicam que 748 milhões de pessoas carecem de uma fonte segura e sustentável de água potável e 2,5 bilhões não possuem acesso às instalações sanitárias adequadas (OMS/UNICEF, 2014). Esta situação acarreta diversos problemas de saúde pública, uma vez que a falta de saneamento e água de qualidade podem levar a morte. Globalmente, as doenças de veiculação hídrica representam a segunda causa de morte de crianças menores de cinco anos, matando 1400 todos os dias (UNICEF/USA, 2014).

O conceito de que água potável e saneamento básico são essenciais para a saúde não é recente. Em 350 a.C., Hipócrates já recomendava ferver a água para inativar as impurezas e diminuir a incidência de doenças. Nos Estados Unidos e Europa Central, onde o saneamento básico é quase universal, as doenças de veiculação hídrica foram reduzidas significativamente no século passado devido à proteção das fontes de água e instalação de sistema de esgotamento sanitário. Nos países em desenvolvimento, entretanto, os serviços de água e esgoto ainda são deficitários resultando em milhões de mortes decorrentes de doenças evitáveis (MONTGOMERY e ELIMELECH, 2007). Nesses países, o abastecimento público de água muitas das vezes não consegue fornecer água com qualidade para o consumo humano, seja pela operação não confiável ou falta de manutenção nas estações de tratamento de água ou ainda pela contaminação secundária durante a coleta, transporte e armazenamento da mesma (GOMES et al. 2009).

A relação entre água e higiene com diarréias foi apontada por Esrey (1996) em um estudo realizado em oito países, Burundi, Gana, Togo, Uganda, Sri Lanka, Marrocos, Bolívia e Guatemala. A maior taxa de doenças diarréicas foi encontrada em locais que não possuíam saneamento básico, enquanto que nos lugares com ótimas condições sanitárias, além de menor incidência dessas doenças, foi verificado que as crianças eram mais altas e apresentavam maiores pesos. Barreto et al. (2007) avaliando os efeitos epidemiológicos decorrentes do aumento da cobertura da rede de esgoto de $26 \%$ para $80 \%$ da população em Salvador, Brasil, verificou a redução de $22 \%$ de doenças diarréicas em crianças menores de três anos, sendo que nos locais com as piores taxas de cobertura de rede de esgoto e mais casos de diarréias, a redução foi de $43 \%$. Em outro estudo realizado em um grande centro na região nordeste do Brasil, Genser et al. (2006) identificaram que os principais determinantes de doenças diarréicas são o baixo poder econômico, escassez em saneamento básico, presença de parasitas intestinais e ausência de exames pré-natal. Assim, o acesso global à água potável e melhorias no saneamento básico são formas menos dispendiosas e mais eficazes para melhorar a saúde pública e salvar vidas, porém, tais medidas ainda têm sido ignoradas.

O Brasil, assim como grande parte dos países em desenvolvimento, possui sérios problemas relacionados ao saneamento básico. De acordo com a Pesquisa Nacional de Saneamento Básico de 2008 (IBGE, 2010), 33 municípios brasileiros declararam a inexistência de rede de abastecimento de água e no caso do sistema de esgotamento sanitário a situação revelou-se preocupante, pois foi verificada a falta de rede coletora de esgoto em 2495 municípios, distribuídos pelas Unidades da Federação. O contingente populacional sem a cobertura desse serviço, considerando apenas os municípios sem rede coletora, era de aproximadamente 34,8 milhões de pessoas, ou seja, 
aproximadamente $18 \%$ da população brasileira estavam expostas ao risco de contrair doenças em decorrência da inexistência de rede coletora de esgoto.

Em Cuiabá, capital do Estado do Mato Grosso, de acordo com o Plano Municipal de Saneamento Básico (CUIABÁ, 2011), o sistema de esgotamento sanitário atende aproximadamente $38 \%$ da população, sendo que somente $28 \%$ contam com os serviços de coleta e tratamento. Tais dados revelam a pressão negativa que os recursos hídricos vem sofrendo pois grande parte desse esgoto acaba sendo descartado diretamente nos córregos urbanos e rios que cortam a cidade. Em relação ao sistema de abastecimento de água de Cuiabá, este é feito por mananciais e poços artesianos atendendo aproximadamente $99 \%$ da população do município, porém de forma intermitente para uma parcela desta população.

O bairro Pedra 90, localizado na região sudeste de Cuiabá, MT, enfrenta problemas de infraestrutura em saneamento básico desde a sua implantação, e isso tem impulsionado a ocorrência de problemas relacionados à falta de água em condições adequadas de quantidade e qualidade. Uma das alternativas da população neste local para usufruir de água foi a abertura de poços rasos (freáticos) nos quintais das residências, alternativa importante para abastecimento de comunidades rurais (SILVA et al. 2014). O objetivo deste trabalho foi avaliar a qualidade microbiológica (Escherichia coli e bactérias heterotróficas mesófilas cultiváveis) e físico-química ( $\mathrm{pH}$, turbidez e condutividade elétrica) desses poços rasos no bairro Pedra 90 e apontar os possíveis riscos à saúde da população.

\section{MATERIAL E MÉTODOS}

\subsection{Seleção dos poços rasos para monitoramento}

O bairro Pedra 90 está localizado na porção sudeste da cidade de Cuiabá, distante aproximadamente $20 \mathrm{~km}$ do centro. Durante a seleção dos poços rasos, procurou-se uma distribuição homogênea na área, a fim de se obter dados para o conhecimento da qualidade microbiológica e físico-química da água em toda a região do bairro. Assim, foram selecionados 17 poços localizados em 17 residências diferentes (Figura 1).

\subsection{Amostragem e análise qualitativa das águas dos poços rasos}

As coletas para avaliação da qualidade da água ocorreram nos meses de novembro/2013, início do período chuvoso e janeiro/2014, período de chuvas mais regulares. As amostras de água foram coletadas em tréplicas com amostradores manuais estéreis do tipo bailer. Para cada poço foi utilizado um amostrador, para não haver a transferência de contaminação de um poço para outro. A amostragem foi efetuada de forma lenta, a fim de evitar agitação da água dentro do poço. Também foi tomado o cuidado para não haver contato do bailer com o fundo do poço, evitando assim movimentação de sedimento. Em seguida, as amostras foram cuidadosamente transferidas para frascos de polietileno estéreis e acondicionadas em caixa térmica contendo gelo, de acordo com os procedimentos de coleta e preservação recomendadas pela ANA/CETESB (2011). Imediatamente após a coleta, as amostras foram transportadas para o laboratório para 
determinação da sua qualidade microbiológica, observando o prazo de 8 horas para a realização das análises.

As análises microbiológicas envolveram a determinação de Escherichia coli utilizando o método do substrato cromogênico e fluorogênico ONPG-MUG (Colilert ${ }^{\circledR}$ ) e a determinação de bactérias heterotróficas mesófilas cultiváveis pelo método de plaqueamento em superfície (spread plate) utilizando como meio de cultura Agar Padrão para Contagem (Himedia). Todos os métodos são indicados pelo Standard Methods of Examination of Water and Wastewater (APHA, 2012).

Além dos parâmetros microbiológicos, foram determinados, no momento da coleta, $\mathrm{pH}$ e condutividade elétrica por meio de medida direta utilizando a Sonda Multiparâmetros Hach HQ40d e turbidez por meio do Turbidímetro Hach 21000.

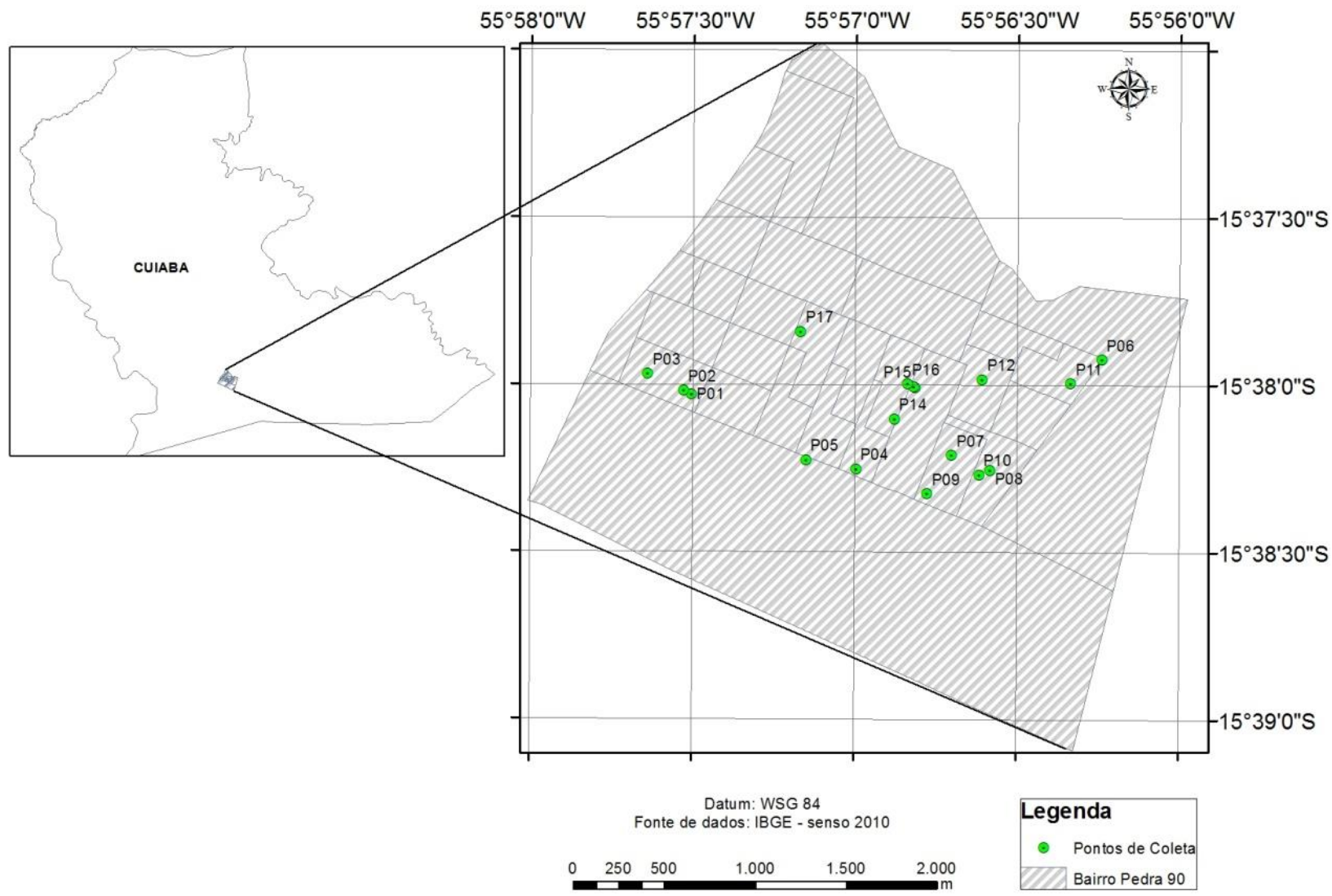

Figura 1: Distribuição espacial dos poços rasos monitorados na região do bairro Pedra 90, Cuiabá, MT.

\subsection{Fatores de riscos à saúde}

Para apontar os possíveis riscos à saúde da população decorrente do uso e consumo das águas dos poços, foi efetuada uma entrevista com os moradores das 17 residências que tiveram a qualidade da água dos poços avaliada. Nesta entrevista foram levantadas informações sobre: 1) o tipo de abastecimento de água e o destino do esgoto gerado na residência, 2) quais os usos da água 
do poço e 3) se há residentes mais suscetíveis às doenças de veiculação hídrica, ou seja, crianças menores de cinco anos e idosos maiores de 65.

\section{RESULTADOS E DISCUSSÃO}

\subsection{Qualidade das águas dos poços rasos}

O controle da qualidade microbiológica das águas é de fundamental importância para a prevenção da ocorrência de doenças de veiculação hídrica. A determinação de bactérias do grupo coliformes, especificamente de Escherichia coli, indica uma poluição fecal da água e a possível presença de patógenos. Já a determinação de bactérias heterotróficas é um importante instrumento auxiliar no controle bacteriológico para avaliação das condições higiênicas e de proteção dos poços e fontes.

A Portaria 2914/2011 do Ministério da Saúde (BRASIL, 2011) recomenda como limite máximo de bactérias heterotróficas mesófilas cultiváveis em amostras de água para consumo humano o valor de $500 \mathrm{UFC} / \mathrm{mL}$. Nos poços rasos do bairro Pedra 90 observaram-se alta densidade dessas bactérias tanto no período de início das chuvas (novembro/2013), quanto no período de chuvas mais regulares (janeiro /2014), sendo que $87,9 \%$ das análises efetuadas apresentaram concentração acima do valor máximo recomendado. As concentrações dessas bactérias variaram entre 160 e 19050 UFC/mL, e apenas os poços P12, P15 e P16 apresentaram valores abaixo do recomendado nas análises efetuadas em novembro/2013 e P15 nas análises de janeiro/2014 (Tabela 1). Vale ressaltar a importância do monitoramento da quantidade de bactérias heterotróficas, visto que, densidades muito elevadas destes microrganismos na água podem determinar a deterioração de sua qualidade, com desenvolvimento de odores e sabores desagradáveis e produção de limo ou películas, além de poder fornecer informações sobre a disponibilidade de nutrientes na água que propiciam o crescimento bacteriano ou presença de microrganismos patogênicos oportunistas, tais como Pseudomonas aeruginosa, Legionella sp. e Aeromonas sp. (CETESB, 2011).

A Escherichia coli é uma bactéria pertencente à família Enterobacteriaceae e única espécie do grupo coliforme cujo habitat exclusivo é o intestino humano e de animais homeotérmicos (APHA, 2012). Sua presença indica contaminação fecal recente, pois não se multiplicam e nem persistem por um longo período, possuindo sobrevivência similar à das bactérias patogênicas (GOMES-SILVA et al. 2014).

Os resultados para E. coli encontrados nos poços rasos do bairro Pedra 90 apontaram que 97,0\% das amostras apresentaram essa bactéria (Tabela 1), estando em desacordo com o estabelecido pela Portaria 2914/2011 do Ministério da Saúde (BRASIL, 2011), pois nas amostras individuais procedentes de poços, fontes, nascentes ou outras formas de abastecimento sem distribuição canalizada, essa bactéria deve estar ausente. No período de início das chuvas as concentrações variaram entre 0,0 e $1694 \mathrm{NMP} / 100 \mathrm{~mL}$ e no período de chuvas regulares, a variação foi de 37 a $1887 \mathrm{NMP} / 100 \mathrm{~mL}$. Os altos valores de $E$. coli encontrados nos dois períodos de amostragem possivelmente estão relacionados à proximidade das águas do aquífero freático com as fossas rudimentares que são comuns na região, indicando uma possível contaminação por 
esgotos domésticos. Em um estudo recente realizado na região do bairro Pedra 90, Silva et al. (2014), após avaliar 31 poços rasos, também constatou contaminação na água por Escherichia coli em $100 \%$ das amostras, evidenciando a falta de saneamento básico e a construção de poços e fossas de forma generalizada e inadequada.

Tabela 1: Valores de bactérias heterotróficas mesófilas cultiváveis (BHMC) e Escherichia coli nas águas dos poços rasos no bairro Pedra 90 em Cuiabá, MT.

\begin{tabular}{c|c|c|c|c}
\hline & \multicolumn{2}{|c|}{ Novembro/2013 } & \multicolumn{2}{c}{ Janeiro/2014 } \\
\cline { 2 - 5 } Poço & BHMC (UFC/mL) & $\begin{array}{c}\text { Escherichia coli } \\
\text { (NMP/100 mL) }\end{array}$ & BHMC (UFC/mL) & $\begin{array}{c}\text { Escherichia coli } \\
(\mathrm{NMP} / 100 \mathrm{~mL})\end{array}$ \\
\hline P1 & $2883 \pm 40$ & $199 \pm 54$ & $1038 \pm 183$ & $1770 \pm 204$ \\
P2 & $1043 \pm 829$ & $672 \pm 289$ & $1078 \pm 48$ & $367 \pm 127$ \\
P3 & $1043 \pm 874$ & $8 \pm 4$ & $1045 \pm 179$ & $174 \pm 82$ \\
P4 & $825 \pm 103$ & $575 \pm 283$ & $1488 \pm 884$ & $362 \pm 194$ \\
P5 & $800 \pm 74$ & $80 \pm 38$ & $1770 \pm 1036$ & $163 \pm 32$ \\
P6 & $723 \pm 40$ & $1073 \pm 23$ & $520 \pm 421$ & $1652 \pm 354$ \\
P7 & $930 \pm 143$ & $871 \pm 435$ & $1582 \pm 189$ & $378 \pm 109$ \\
P8 & $955 \pm 97$ & $1458 \pm 474$ & $720 \pm 264$ & $1818 \pm 323$ \\
P9 & $923 \pm 44$ & $1073 \pm 641$ & $660 \pm 18$ & $1009 \pm 634$ \\
P10 & $570 \pm 141$ & $31 \pm 19$ & $1207 \pm 543$ & $37 \pm 22$ \\
P11 & $16767 \pm 5689$ & $1694 \pm 771$ & $19050 \pm 6780$ & $238 \pm 16$ \\
P12 & $160 \pm 69$ & $183 \pm 50$ & $1323 \pm 65$ & $1887 \pm 204$ \\
P13 & $658 \pm 250$ & $273 \pm 57$ & $1257 \pm 377$ & $273 \pm 57$ \\
P14 & $16683 \pm 9930$ & $991 \pm 1293$ & $18533 \pm 8109$ & $1701 \pm 283$ \\
P15 & $463 \pm 442$ & $17 \pm 22$ & $402 \pm 289$ & $43 \pm 25$ \\
P16 & $150 \pm 71$ & $0 \pm 0$ & $1413 \pm 351$ & $87 \pm 24$ \\
P17 & $1328 \pm 488$ & $20 \pm 11$ & $\mathrm{nd}$ & $\mathrm{nd}$ \\
\hline
\end{tabular}

nd = não determinado.

Nos poços estudados, os valores de turbidez variaram de 0,30 UNT (P15) à 40,07 UNT (P8), com aumento dos valores desse parâmetro em alguns dos poços na segunda coleta, período de chuvas mais intensas (Tabela 2). Esta situação possivelmente é devido ao carreamento e lixiviação das paredes dos poços que não possuem proteção adequada, fazendo com que aumente a concentração de partículas em suspensão e a turvação da água. Para a garantia da qualidade microbiológica da água, em complementação às exigências relativas aos indicadores microbiológicos, a Portaria 2914/2011 do Ministério da Saúde (BRASIL, 2011), determina que seja atendido o padrão de turbidez, para águas subterrâneas, de 1,0 UT (unidade de turbidez), pois a presença de sólidos suspensos elevando a turbidez é um fator que pode servir de escudo para os microrganismos, camuflando os mesmos e dificultando a detecção de alguns gêneros de bactéria que podem vir a causar danos a saúde da população. No período de menos chuva (primeira coleta) apenas os poços P5, P6, P10 e P15, apresentaram valores abaixo do valor estabelecido pela Portaria. No período de maior intensidade de chuvas (segunda coleta), apenas o poço P9 apresentou conformidade. Assim, 84,9\% dos valores de turbidez obtidos nas duas campanhas estiveram acima do padrão estabelecido.

Tabela 2: Valores de turbidez, condutividade elétrica e pH nas águas dos poços rasos no bairro Pedra 90 em Cuiabá, MT. 


\begin{tabular}{c|c|c|c|c|c|c}
\hline Poço & $\begin{array}{c}\text { Turbidez } \\
\text { (UNT) }\end{array}$ & $\begin{array}{c}\text { Condutividade } \\
\text { elétrica (S/cm) }\end{array}$ & $\mathrm{pH}$ & $\begin{array}{c}\text { Turbidez } \\
(\text { UNT) }\end{array}$ & $\begin{array}{c}\text { Condutividade } \\
\text { elétrica }(\mu \mathrm{S} / \mathrm{cm})\end{array}$ & $\mathrm{pH}$ \\
\hline P1 & $6,39 \pm 0,47$ & $118,7 \pm 24,1$ & 6,96 & $4,30 \pm 1,92$ & $116,1 \pm 0,5$ & 5,74 \\
P2 & $8,92 \pm 0,25$ & $81,4 \pm 0,3$ & 6,31 & $12,90 \pm 0,46$ & $111,3 \pm 0,3$ & 6,41 \\
P3 & $22,83 \pm 1,35$ & $480,3 \pm 3,1$ & 6,86 & $34,27 \pm 2,15$ & $486,7 \pm 3,5$ & 6,69 \\
P4 & $1,33 \pm 0,29$ & $190,5 \pm 1,1$ & 6,37 & $2,20 \pm 1,16$ & $195,1 \pm 2,9$ & 6,75 \\
P5 & $0,57 \pm 0,11$ & $118,7 \pm 1,0$ & 5,39 & $4,18 \pm 1,65$ & $174,0 \pm 0,9$ & 6,09 \\
P6 & $0,53 \pm 0,23$ & $119,6 \pm 0,5$ & 5,32 & $2,71 \pm 0,57$ & $119,6 \pm 0,5$ & 6,04 \\
P7 & $1,24 \pm 00,5$ & $211,2 \pm 1,9$ & 4,46 & $5,23 \pm 0,24$ & $228,5 \pm 5,3$ & 5.02 \\
P8 & $2,98 \pm 1,12$ & $82,3 \pm 4,5$ & 4,46 & $40,07 \pm 7,13$ & $82,3 \pm 4,5$ & 6,15 \\
P9 & $1,73 \pm 0,64$ & $393,0 \pm 1,7$ & 5,60 & $0,77 \pm 0,29$ & $393,0 \pm 1,7$ & 6,02 \\
P10 & $0,41 \pm 0,07$ & $263,3 \pm 0,6$ & 4,79 & $8,42 \pm 0,76$ & $104,2 \pm 9,0$ & 6,67 \\
P11 & $1,47 \pm 0,16$ & $164,9 \pm 11,5$ & 5,99 & $2,86 \pm 1,37$ & $212,3 \pm 3,8$ & 5,42 \\
P12 & $7,88 \pm 1,37$ & $115,0 \pm 12,8$ & 5,44 & $8,33 \pm 1,30$ & $115,0 \pm 12,8$ & 6,03 \\
P13 & $5,02 \pm 0,04$ & $125,9 \pm 0,2$ & 5,53 & $4,41 \pm 0,75$ & $109,9 \pm 2,0$ & 5,56 \\
P14 & $2,09 \pm 0,05$ & $129,0 \pm 0,3$ & 5,11 & $4,27 \pm 0,86$ & $129,0 \pm 0,3$ & 5,88 \\
P15 & $0,30 \pm 0,04$ & $148,4 \pm 0,6$ & 5,56 & $4,29 \pm 0,86$ & $153,8 \pm 3,6$ & 5,59 \\
P16 & $8,33 \pm 4,41$ & $181,3 \pm 0,4$ & 5,82 & $14,90 \pm 0,80$ & $224,6,3 \pm 9,5$ & 5,88 \\
P17 & $10,58 \pm 0,63$ & $260,7 \pm 1,2$ & 6,18 & nd & nd & nd \\
\hline
\end{tabular}

Para $\mathrm{pH}$ não foi considerado a média por se tratar de um valor logaritimizado. nd $=$ não determinado.

Os valores de condutividade elétrica variaram de $81,4 \mu \mathrm{S} / \mathrm{cm}$ (P2) a 486,7 $\mu \mathrm{S} / \mathrm{cm}$ (P3). Este parâmetro sofre influência das características hidrogeológicas da região e também da contaminação por esgoto doméstico provenientes de fossas rudimentares. O aumento da condutividade no período chuvoso possivelmente é decorrente do aumento do nível do aquífero freático, aliado ao aumento de sais dissolvidos e partículas, bem como pela contaminação por esgoto doméstico.

Nos poços estudados, os resultados de $\mathrm{pH}$ encontrados indicaram uma água tendendo a ácida, variando entre 4,46 (P7 e P8) a 6,96 (P1). Os resultados da primeira coleta quando comparados com os da segunda mostram uma tendência de aumento, que pode ter sido provocado pelo aumento gradativo na intensidade das chuvas que contribui para a diluição dos íons $\mathrm{H}^{+} \mathrm{e}$ a lixiviação das rochas carbonáticas (lentes de calcário), comum na região (MIGLIORINI, 2004). A maioria das águas subterrâneas tem pH entre 5,5 e 8,5. Em casos excepcionais pode variar entre 3 e 11 (FEITOSA e MANOEL FILHO, 1997). Silva et al. (2014), em estudos efetuados na mesma região investigada por esse trabalho, encontrou resultados de $\mathrm{pH}$ que indicaram uma água tendendo a ácida, cujo valores variaram entre 4,1 e 6,8.

\subsection{Riscos à saúde da população}

Uma grande variedade de microrganismos patogênicos pode ser encontrada em excrementos de seres humanos e de outros animais de sangue quente. Por isso, a contaminação de águas por fezes é uma das formas mais importantes de introdução de patógenos nas águas. Esgotos urbanos e industriais e águas de escoamento superficial de áreas habitadas (urbana e rural) são exemplos importantes de veículos carreadores de patógenos para os recursos hídricos.

As doenças veiculadas por água contaminada se manifestam principalmente como diarréias que levam a estados mórbidos duradouros e até quadros de desidratação e morte se não forem repostos os sais e líquidos perdidos. Os principais causadores destas doenças são diferentes grupos de bactérias, vírus, protozoários e helmintos. Embora os vírus não sejam pesquisados com 
frequência na água ou hospedeiro, eles podem responder pela maior parte de agentes causadores, seguidos pelos demais parasitas. As doenças mais comuns relacionados à má qualidade da água e falta de saneamento básico são: salmoneloses (disenterias e febre tifóide), shigeloses (disenteria bacilar), cólera, leptospirose, hepatite, diarréias por rotavírus, esquistossomose, amebíase, giardíase, ascaridíase, estrongiloidíase, entre outras (UNICEF, 2006).

Nas residências que tiveram a qualidade das águas dos poços rasos avaliadas, o abastecimento de água é feito pela empresa concessionária de saneamento do município, porém de forma intermitente. Assim, os poços rasos se tornaram alternativa para o abastecimento de água. No bairro Pedra 90 não há rede de esgotamento sanitário e o esgoto gerado nas residências participantes do estudo é descartado em fossas sépticas e rudimentares, que em muitas das vezes estão próximas aos poços rasos. Tal situação, aliada ao fato do nível d'água do aquífero freático na região ser raso, aumenta a vulnerabilidade do mesmo à contaminação. Silva et al. (2014) já haviam apontado que o uso generalizado de fossas sépticas, rudimentares e drenos no bairro Pedra 90, onde os esgotos são lançados sobre ou abaixo da superfície do solo, tem contribuído para a contaminação das águas subterrâneas no local.

As águas dos poços rasos nas residências estudadas são utilizadas pelos moradores principalmente para higiene pessoal e lavagens em geral (quintais, roupas e louças utilizadas em cozinha), mas também é consumida em sete das residências avaliadas sendo que em apenas duas delas os moradores utilizam algum método de desinfecção (fervura) antes do consumo. Uma vez identificado que essas águas possuem contaminação por $E$. coli e bactérias heterotróficas, elas são impróprias ao consumo humano por possivelmente conter microrganismos patogênicos. Deve ser destacado também que o uso dessas águas para a higiene pessoal também representa riscos à saúde humana. Os riscos podem ser maiores para aquelas pessoas mais suscetíveis às doenças de veiculação hídrica, ou seja, crianças menores de cinco anos e idosos com mais de 65 anos, e nesse estudo, verificou-se que em doze residências há crianças e/ou idoso com esta faixa etária.

\section{CONCLUSÕES}

O acesso universal e de qualidade ao saneamento básico no Brasil ainda é um grande desafio. Os déficits desse setor denunciam que os direitos básicos como acesso à água e ao destino seguro dos dejetos nem sempre são assegurados. No bairro Pedra 90 em Cuiabá, MT, as águas dos poços rasos utilizados pela população apresentam contaminação por Escherichia coli e bactérias heterotróficas, estando impróprias para consumo humano. Tal contaminação é decorrente principalmente do destino incorreto do esgoto doméstico na região, que em sua maioria é feito por meio de fossas rudimentares. Foi verificado que as águas desses poços são utilizadas, dentre outros fins, para consumo e higiene pessoal, representando risco à saúde da população. Sendo o saneamento do meio uma estratégia na mitigação ou reversão dos impactos negativos das modificações ambientais, esse deve ser prioridade do poder público para assim, garantir a qualidade de vida da população. 


\section{AGRADECIMENTOS}

Os autores agradecem ao Conselho Nacional de Desenvolvimento Científico e Tecnológico (CNPq) pelo auxílio financeiro.

\section{REFERÊNCIAS}

1. ANA/CETESB. Guia nacional de coleta e preservação de amostras - Água, sedimento, comunidades aquáticas e efluentes líquidos. Agência Nacional das Águas/Companhia Ambiental do Estado de São Paulo, Brasília: ANA, 2011, 325p.

2. APHA - AMERICAN PUBLIC HEALTH ASSOCIATION. Standard methods for the examination of water and wastewater. 22a ed. Washington: American Public Health Association/American Water Works Association/Water Pollution Control Federation, 2012.

3. BARRETO, M.L., GENSER, B., STRINA, A., TEIXEIRA, M.G., ASSIS, A.M.O., REGO, R.F., TELES, C.A., PRADO, M.S., MATOS, S.M.A., SANTOS, D.N., SANTOS, L.A., CAIRNCROSS, S. Effect of city-wide sanitation programme on reduction in rate of childhood diarrhoea in northeast Brazil: assessment by two cohort studies. Lancet, v.370, p.1622-1628, nov. 2007.

4. BRASIL. Ministério da Saúde. Portaria 2914, de 12 de dezembro de 2011. Dispõe sobre os procedimentos de controle e de vigilância da qualidade da água para consumo humano e seu padrão de potabilidade. Disponível em: <http://bvsms.saude.gov.br/bvs/saudelegis/gm/ 2011/prt2914_12_12_2011.html> Acesso em: 15 Dez. 2014.

5. CETESB - COMPANHIA DE TECNOLOGIA E SANEAMENTO AMBIENTAL. Qualidade das águas superficiais no Estado de São Paulo. São Paulo: CETESB, 2011. 342p.

6. CUIABÁ. Plano municipal de saneamento básico - Abastecimento de água e esgotamento sanitário. Cuiabá, 2011, 77p.

7. ESREY, E.A. Water, waste, and well-being: A multicountry study. American Journal of Epidemiology, v.143, n.6, p.608-623, mar. 1996.

8. FEITOSA, F.A.C., MANOEL FILHO, J. Hidrogeologia: conceitos e aplicações. Fortaleza: CPRM, LABHID-UFPE, 1997. 412p.

9. GENSER, B., STRINA, A., TELES, C.A., PRADO, M.S., BARRETO, M.L. Risk factors for childhood diarrhea incidence: dynamic analysis of a longitudinal study. Epidemiology, v.17, n.6, p.658-667, nov. 2006.

10. GOMES, A.I., VILAR, V.J.P., BOAVENTURA, R.A.R. Synthetic and natural waters disinfection using natural solar radiation in a pilot plant with CPCs. Catalysis Today, v.144, p.55-61, jun. 2009.

11. GOMES-SILVA, P.A.J, LIMA, S.D.; GOLIN, R., FIGUEIREDO, D.M., LIMA, Z.M., MORAIS, E.B., DORES, E.F.G.C. Qualidade da água de uma microbacia com fins de abastecimento público, Chapada dos Guimarães, MT. Holos, v.4, p.22-33, 2014.

12. IBGE. Pesquisa Nacional de Saneamento Básico 2008. Rio de Janeiro: Instituto Brasileiro de Geografia e Estatística. 2010, 218p.

13. MONTGOMERY, M.A., ELIMELECH, M. Water and sanitation in developing countries: Including health in the equation. Environmental Science \& Technology, v.1, p.17-24, jan. 2007. 
14. OMS/UNICEF. Progress on sanitation and drinking-water: 2014 Update. Geneva/New York: World Health Organization/United Nations Children's Fund. 2014. 76p.

15. UNICEF. Progress for children: A report card on water and sanitation. New York: UNICEF, 2006.

16. UNICEF/USA. Water and Sanitation. Disponível em: <http://www.unicefusa.org/mission/ survival/water> Acesso em 26 de Dez. 2014.

17. SILVA, D.D., MIGLIORINI, R.B., SILVA, E.C., LIMA, Z.M.; MOURA, I.B. Falta de saneamento básico e as águas subterrâneas em aquífero freático: região do Bairro Pedra Noventa, Cuiabá (MT). Engenharia Sanitária e Ambiental, v.19, n.1, p.43-52, jan/mar. 2014. 